\title{
PLANO DE EMPREENDIMENTO: AGUS
}

Recebido em 02.04.2017. Aprovado em 30.04.2017 Avaliado pelo sistema double blind review

Arthur Couto de Azevedo

azevedoarthur@id.uff.br

Departamento de Empreendedorismo e Gestão - Universidade Federal Fluminense - Niterói -RJ

\section{Sumário Executivo}

AAgus é uma empresa de Kombucha, um probiótico derivado da cultura de bactérias e leveduras que trazem diversos benefícios para a saúde de quem as consome. A bebida será uma mistura do probiótico com suco de frutas orgânicas e outros ingredientes de alta qualidade. E esse não será o único diferencial da empresa, ela traz uma forte proposta de estilo de vida saudável e consciência ambiental. Em apoio e valorização aos produtores locais, serão utilizados frutas e ingredientes da região, sempre que possível. Atualmente, os maiores mercados consumidores de Kombucha estão na América do Norte e na Ásia. No Brasil, o mercado para esse tipo específico de produto é ainda embrionário, mas pesquisas revelam que ele vem crescendo e a tendência é aumentar cada vez mais nos próximos anos. Nosso público-alvo são consumidores que valorizam a saúde e prezam pelo bem-estar. Com base no plano financeiro o negócio se mostrou viável e atrativo, com um investimento inicial de $\mathrm{R} \$ 463.864,11$.

Palavras-chaves: Plano de Empreendimento; Kombucha; Probióticos; Empreendedorismo. 


\section{A Agus}

É saúde.

A ideia do empreendimento surgiu em uma conversa entre mãe e filho. Enquanto trabalhávamos na nossa produção caseira de probióticos, eu e minha mãe percebemos que havia um grande potencial naquilo que estávamos fazendo. Até o momento produzíamos somente para consumo próprio, mas imaginamos que poderíamos gerar valor para a sociedade oferecendo saúde e bem-estar através dos nossos produtos. Assim, identificamos a oportunidade de produzir uma bebida diferenciada, trazendo um produto inovador para a região do Rio de Janeiro.

A Agus nasce como uma marca de Kombucha, um probiótico derivado da cultura de bactérias e leveduras que trazem diversos benefícios para a saúde de quem as consome. A bebida será uma mistura do probiótico com suco de frutas orgânicas e outros ingredientes de alta qualidade. E esse não será o único diferencial da empresa, ela traz uma forte proposta de estilo de vida saudável e consciência ambiental. Em apoio e valorização aos produtores locais, serão utilizados frutas e ingredientes da região, sempre que possível.

Atualmente, os maiores mercados consumidores de Kombucha estão na América do Norte e na Ásia. No Brasil, o mercado para esse tipo específico de produto é ainda embrionário, mas pesquisas revelam que ele vem crescendo e a tendência é aumentar cada vez mais nos próximos anos.

O compromisso com a saúde dos nossos clientes e com o meio ambiente é de extrema relevância para toda e qualquer ação que a empresa venha a realizar. Portanto, é parte fundamental da estratégia da Agus.

\section{Os empreendedores}

\section{AAgus é fruto do estilo de vida e das paixões da família Couto de Azevedo.}

Os sócios do negócio serão Arthur Azevedo e Maria Eduarda Azevedo, mãe e filho. Pretendemos unir nosso conhecimento para gerar o melhor produto e o melhor empreendimento, o quanto for possível.

Arthur, jovem estudante de Empreendedorismo e Gestão, tem um interesse especial pela área de processos. Sua maior ambição é criar um negócio que influencie positivamente a vida das pessoas. Fica responsável por desenvolver o modelo de negócios e posteriormente pela gestão do mesmo.

M. Eduarda, formada em Medicina, com especialização em Neuropediatria e gosto especial pela Medicina tradicional Chinesa (origem dos produtos adotados pela Agus). Ela tem amplo conhecimento sobre produção de probióticos e suas propriedades, além de acompanhar o mercado há anos.

\section{Descrição legal}

Nome de Registro: Agus Ltda.

A Agus será uma sociedade de responsabilidade limitada. Dessa maneira, os sócios podem proteger seu patrimônio pessoal definindo responsabilidades limitadas ao valor do capital social. Esse modelo torna a gestão dos processos internos e dos lucros mais equilibradas, pois cada sócio sabe qual é a sua participação no negócio.

Com a sociedade estabelecida, as responsabilidades internas da empresa passam a ser auto gerenciáveis. No funcionamento ideal, respeitando a autonomia da empresa, qualquer gasto que surja depois da abertura passa a ser de responsabilidade da empresa, e não diretamente do capital dos sócios.

Para regularizar a Agus como sociedade limitada, é necessário fazer o registro na Junta Comercial e solicitar a inscrição em órgãos como:

- Receita Federal, para emissão do CNPJ.

- Secretaria da Fazenda, para inscrição estadual e ICMS.

- Prefeitura, para concessão do alvará de funcionamento. 
Devido a natureza do empreendimento, será necessária autorização de órgãos específicos, como Vigilância Sanitária e entidade responsável pelas liberações ambientais.

\section{Organização e Governança}

Diferente do comum, a Agus não apresenta uma organização topdown com uma hierarquia rígida. Apresentamos nossa estrutura por áreas e principais processos.

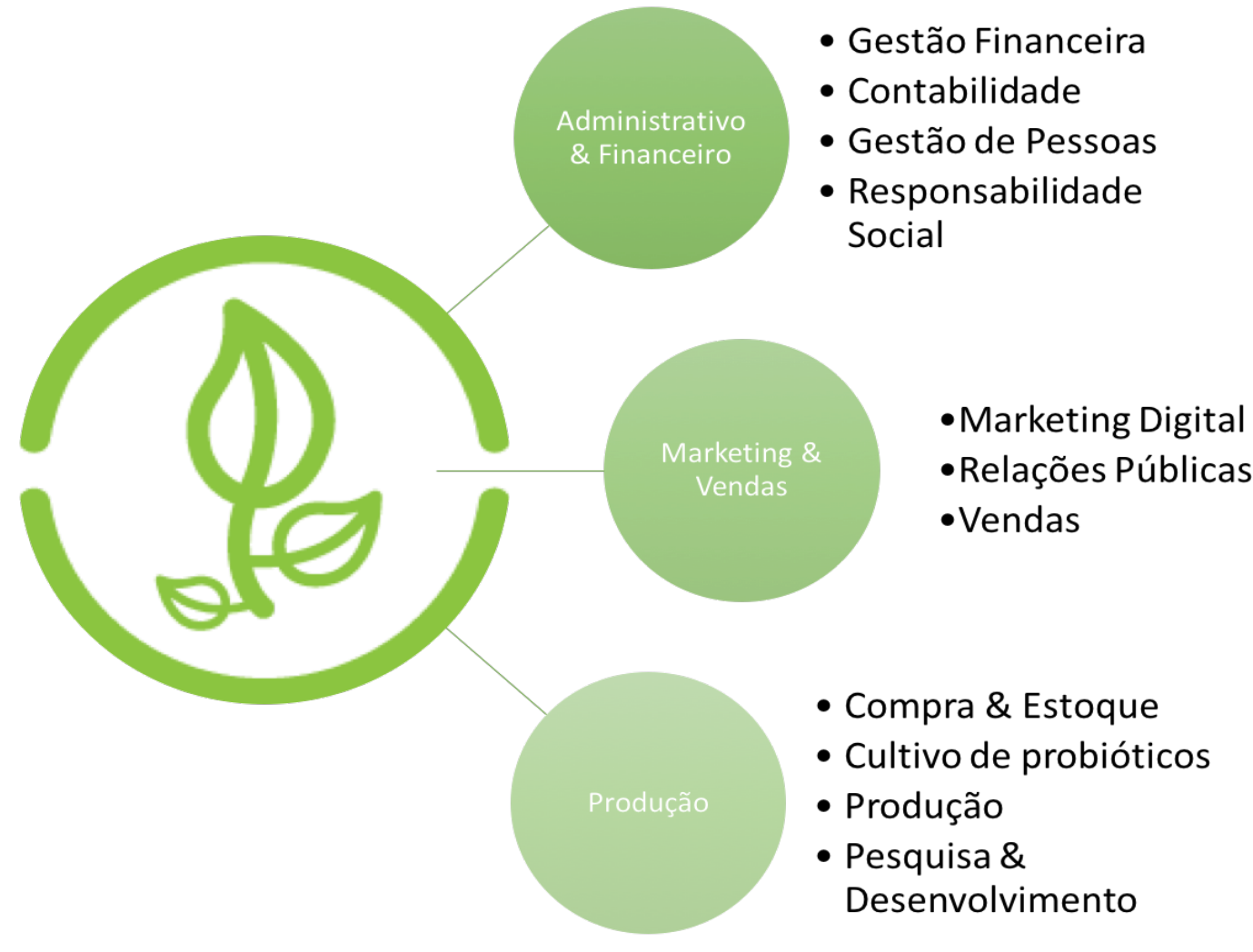

Figura 1: Organograma

Fonte: Elaboração própria.

As principais áreas são: Administrativo \& Financeiro, Marketing \& Vendas e Produção. Para cada Área há um responsável e colaboradores específicos, apresenta-se o quadro:

\begin{tabular}{|l|l|l|l|l|}
\hline \multicolumn{2}{|l|}{ Quadro de colaboradores } \\
\begin{tabular}{|l|l|l|l|} 
Administrativo \\
Financeiro
\end{tabular} & Arthur & Secretária & - & - \\
\hline Marketing \& Vendas & Gerente 1 & Col. 1 & - & - \\
\hline Produção & Eduarda & Eng. Químico & Col. 1 & Col. 2 \\
\hline
\end{tabular}

\section{Tabela 1: Quadro de colaboradores}

Fonte: Elaboração própria 


\section{Arthur Couto de Azevedo}

\section{Principais processos e atribuição de responsabilidades}

Os principais processos de trabalho estão relacionados na tabela a seguir. Para designar as atribuições de cada um dos envolvidos, utilizou-se uma Matriz RACl, onde:

- R: Responsável por executar uma atividade (o executor);

- A: Autoridade, quem deve responder pela atividade, o dono (apenas uma autoridade pode ser atribuída por atividade);

- C: Consultado, quem deve ser consultado e participar da decisão ou atividade no momento que for executada;

- I: Informado, quem deve receber a informação de que uma atividade foi executada.

\begin{tabular}{|c|c|c|c|c|c|c|c|}
\hline \multicolumn{8}{|l|}{ Matriz RACl } \\
\hline & Arthur & Secretária & Eduarda & $\begin{array}{l}\text { Eng. } \\
\text { Químico }\end{array}$ & $\begin{array}{l}\text { Col. } \\
\text { Prod. } 1\end{array}$ & $\begin{array}{l}\text { Col. } \\
\text { Prod. } 2\end{array}$ & Vendedor \\
\hline Gestão Financeira & $R / A$ & & & & & & \\
\hline Contabilidade & $\mathrm{R} / \mathrm{A}$ & & & & & & C \\
\hline Gestão de Pessoas & $\mathrm{R} / \mathrm{A}$ & $\mathrm{C} / \mathrm{l}$ & $\mathrm{C} / \mathrm{l}$ & $\mathrm{C} / \mathrm{l}$ & $\mathrm{C} / \mathrm{l}$ & $\mathrm{C} / \mathrm{l}$ & $\mathrm{C} / \mathrm{l}$ \\
\hline $\begin{array}{l}\text { Responsabilidade } \\
\text { Social }\end{array}$ & $\mathrm{R} / \mathrm{A}$ & 1 & $\mathrm{C} / \mathrm{l}$ & I & 1 & 1 & 1 \\
\hline Marketing Digital & $A / C / I$ & $R$ & & & & & \\
\hline Relações Públicas & & $\mathrm{R}$ & & & & & \\
\hline Vendas & $\mathrm{C} / \mathrm{l}$ & & $\mathrm{C} / \mathrm{l}$ & & & & $R$ \\
\hline Compra \& Estoque & $\mathrm{C} / \mathrm{l}$ & & $\mathrm{R} / \mathrm{A}$ & & & $R$ & \\
\hline Cultivo de Probióticos & & & $A / C / I$ & $\mathrm{R}$ & & & \\
\hline Produção & & & $\mathrm{A} / \mathrm{C} / \mathrm{l}$ & $\mathrm{R}$ & $R$ & & 1 \\
\hline $\begin{array}{l}\text { Pesquisa } \quad \text { \& } \\
\text { Desenvolvimento }\end{array}$ & $\mathrm{C} / \mathrm{I}$ & & $A$ & $\mathrm{R}$ & & & \\
\hline
\end{tabular}

\section{Tabela 2: Matriz RACl}

Fonte: Elaboração própria. 


\section{A fábrica}

A fábrica da empresa será construída em módulos de containers reutilizados. Além de ter impacto ambiental reduzido, quando comparado a uma estrutura tradicional, o custo é consideravelmente menor.

\section{Construção}

- Estima-se uma área de $308 \mathrm{~m}^{2}$ para a fábrica, ou seja, 11 módulos de $28 \mathrm{~m}^{2}$.

A área de instalação sugerida para a fábrica é de $228 \mathrm{~m}^{2}$ para área de produção e de $80 \mathrm{~m}^{2}$ para área de escritório administrativo.

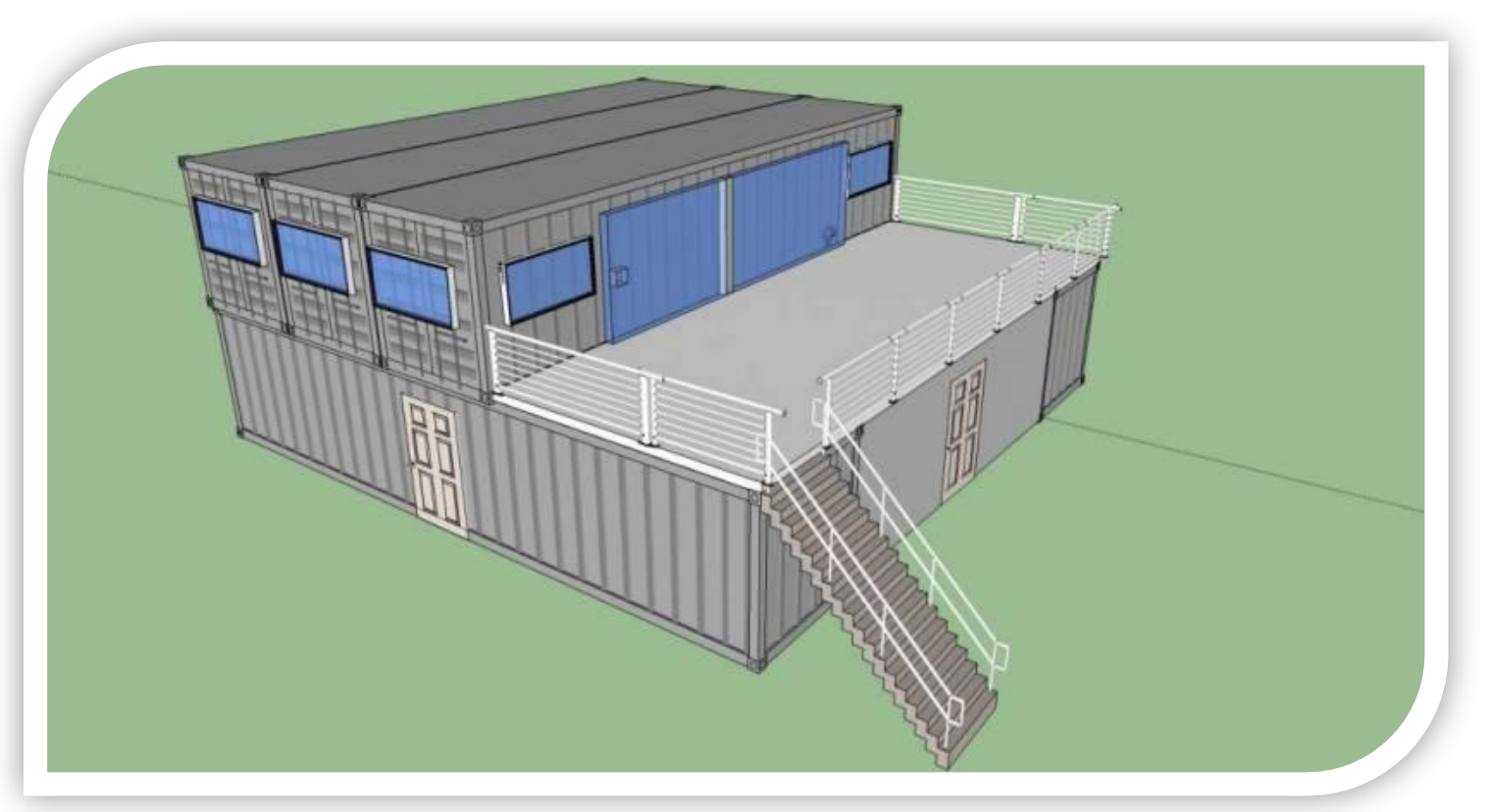

Figura 2: A fábrica

Fonte: Elaboração própria.

\section{Maquinas essenciais}

- Tipo: Lavador de frutas

\section{Quantidade: 1}

\section{Material: Aço inox}

Processos: Banho por imersão clorificada; escovagem; lavagem final.

Obs.: Três tanques individuais (incluiu conexões para entradas e saídas de água para cada um dos tanques) que são equipados com duchas individuais.

Capacidade: $120 / 150 \mathrm{Kg}$

Rendimento: $120 / 150 \mathrm{Kg}$ por $2 \mathrm{hr}$.

- Máquina: Extração de sucos 
Quantidade: 1

Material: Aço inox

Processos: Extração de sucos por Arraste de Vapor.

Obs.: Tanque individual (inclui conexão para o tanque de mistura) equipado com ducha.

Capacidade: $18 \mathrm{Kg}$

Rendimento: $14,5 \mathrm{~L}$ por $2 \mathrm{hrs}$

- Máquina: Tanque de cultura

Quantidade: 30

Material: Aço inox 304

Processos: Cultivo de Kombucha

Obs.:

Capacidade: $60 \mathrm{~L}$

Rendimento: 60L por 15 dias

- Máquina: Tanque de mistura

Quantidade: 1

Material: Aço inox 304

Processos: Mistura final (kombuchá + sucos/chás)

Obs.: Tanque individual, equipado com misturador acionado por motor, com ducha e saída para Máquina Envasadora.

Capacidade: 250L

Rendimento: 250L por $2 \mathrm{Hr}$

- Máquina: Máquina Envasadora

Quantidade: 1

Material: Aço inox 304

Processos: Envasamento de Kombucha final

Obs.: Tanque individual, equipado com entradas para Tanque de Mistura. Preenchimento automático e semiautomático de garrafas de $250 \mathrm{ml} \mathrm{e} 1 \mathrm{~L}$.

Capacidade: $20 \mathrm{~L}$

Rendimento: 20L por 10 minutos

- Máquina: Higienizador de garrafas

Quantidade: 1

Material: -

Processos: Higienização das garrafas de vidro. 
Obs.: Este equipamento é vital para comprimento das normas sanitárias e garantir a preservação do produto. Equipado com bicos para jatos de água ascendentes, com adaptação para o encaixe de garrafas com a boca posicionada para baixo.

Capacidade: 20 garrafas

Rendimento: 400 garrafas por hora

\section{Análise de Mercado}

\section{Panorama e dimensionamento}

O Brasil é o quinto maior mercado de alimentos e bebidas saudáveis do mundo, o volume de vendas atingiu aproximadamente US\$27,5 bilhões em 2015, segundo levantamento da EROMONITOR, detalhado na figura 3.

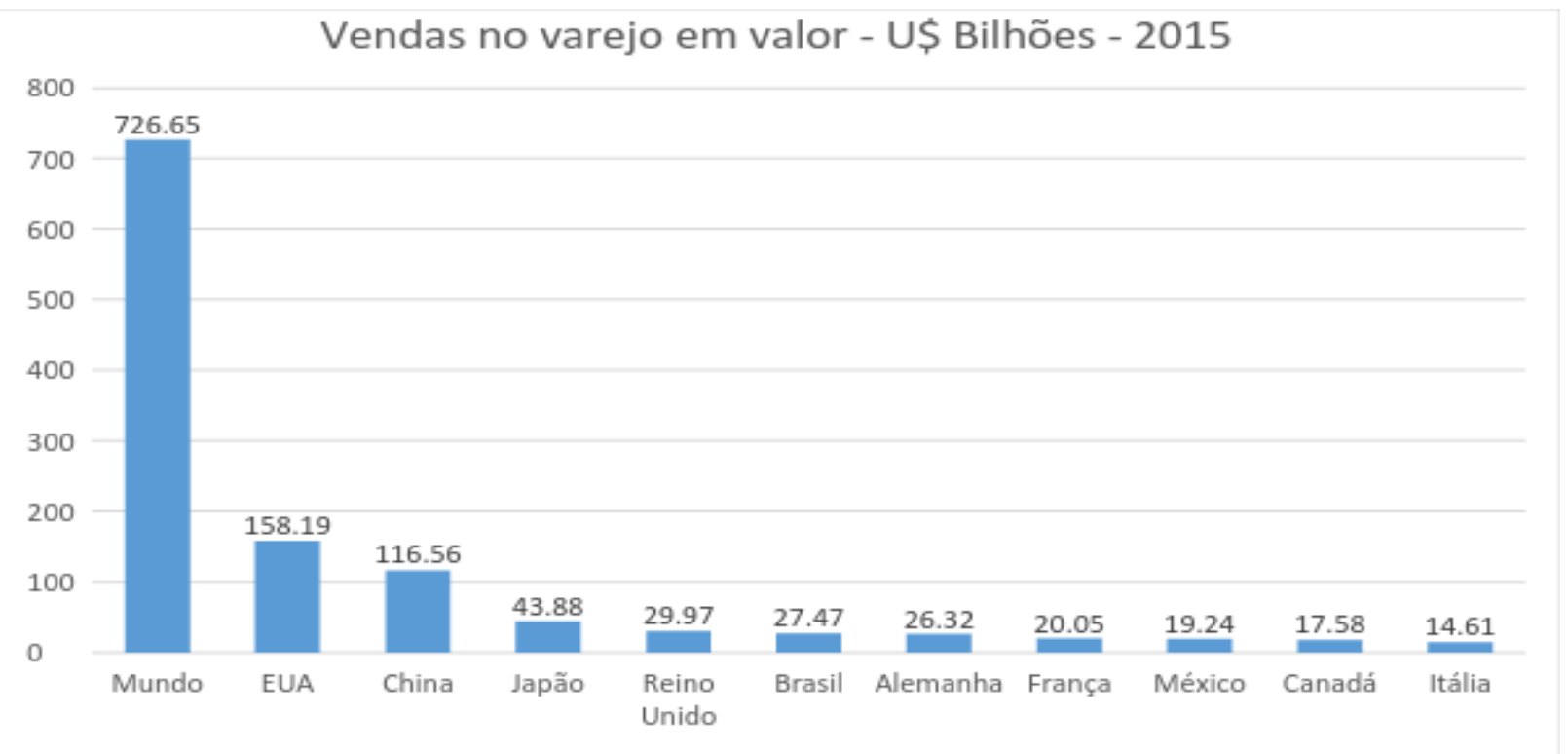

Figura 3: Vendas de alimentos saudáveis no varejo no mundo

Fonte: EUROMONITOR (2015)

Esse mercado cresceu 98\% no Brasil entre 2009 e 2014. E a agência prevê um crescimento expansivo do setor até 2020; os produtos que apresentarem maior grau de diversificação se destacarão por consequência do novo comportamento do consumidor, cada vez mais interessado nesse mercado. 
Vendas no varejo - U\$ Bilhões - 2015 a 2020

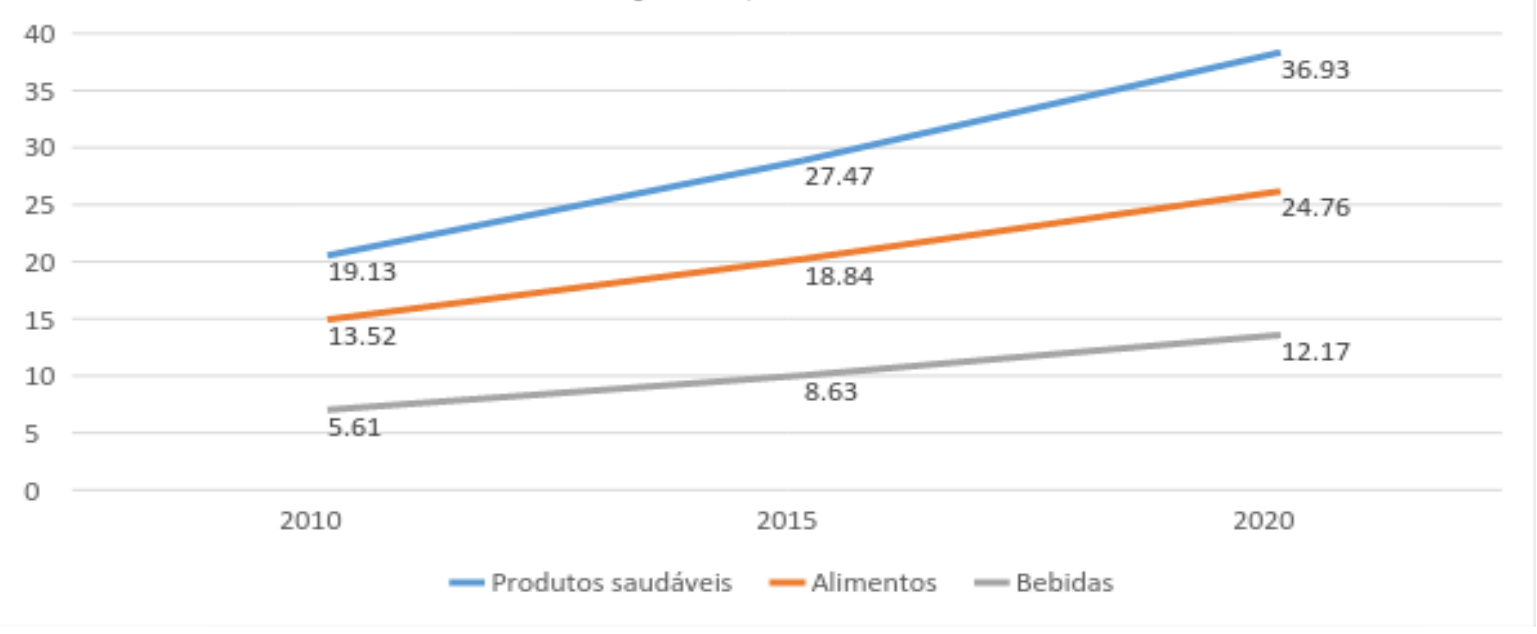

Figura 4: Vendas de produtos saudáveis do varejo no Brasil Fonte: ABIR (2016)

Mais especificamente no mercado de bebidas, segundo dados da ABIR (Associação Brasileira das Indústrias de Refrigerantes e Bebidas não alcoólicas), em 2015 o volume de produção de sucos naturais no Brasil foi de 1.258.103 Litros, conforme apresentado na figura 3.

\section{Volume de produção (em Litros) do mercado brasileiro de} sucos naturais dos de 2010 a 2015

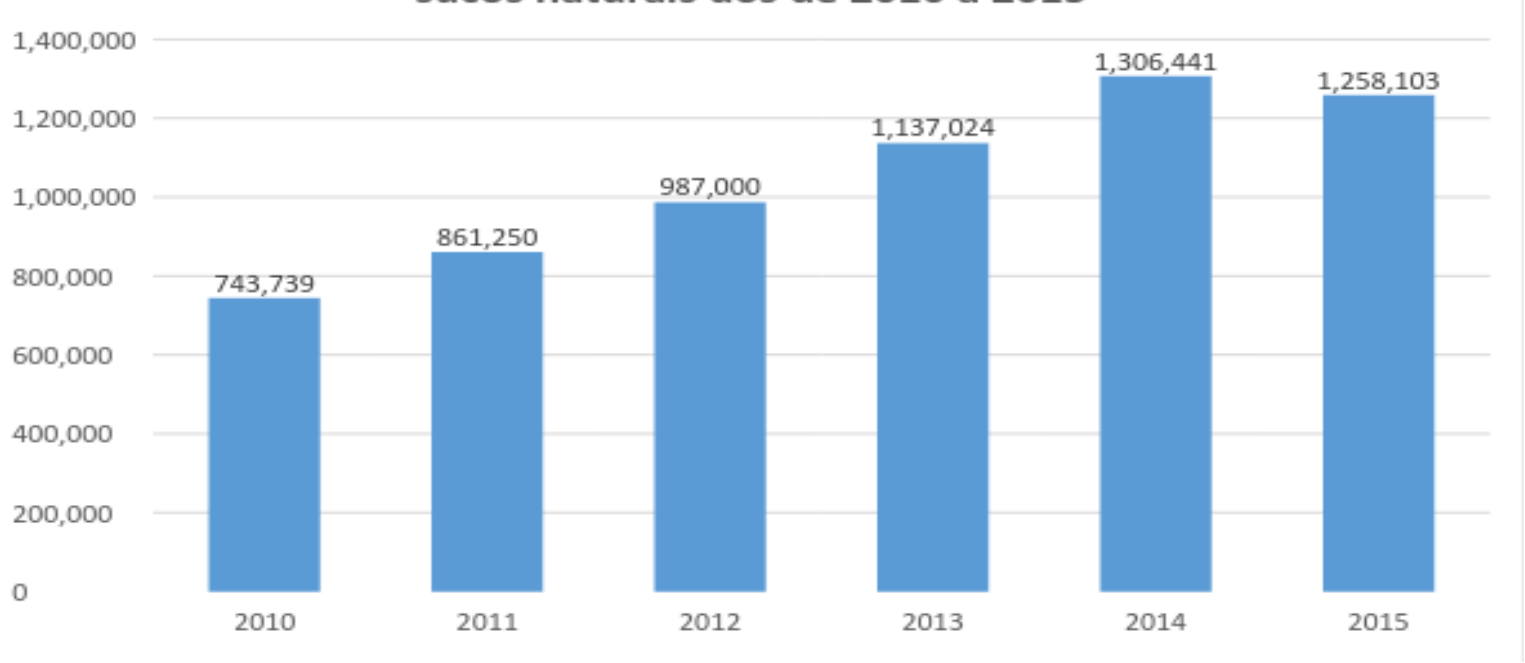

Figura 6: Volume de produção de sucos naturais no Brasil Fonte: ABIR (2016)

Apesar do forte crescimento, o consumo em litros por pessoas por ano ainda é baixo se comparado com os maiores mercados do mundo. Apenas 6,2 L/Habitante em 2015. 


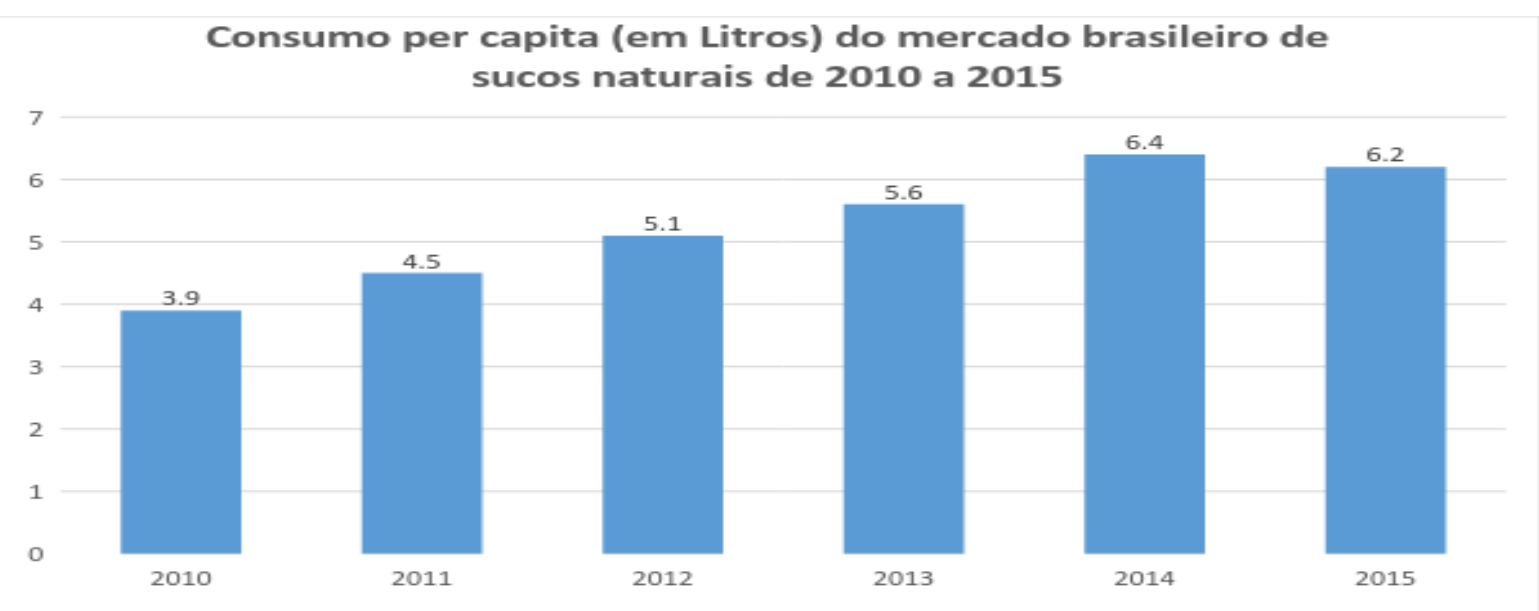

Figura 5: Consumo de sucos per capita no Brasil

Fonte: ABIR (2016)

\section{Público-alvo: perfil e hábitos de consumo}

A crescente busca por qualidade de vida, através de hábitos alimentares mais saudáveis, gera oportunidades para os sucos $100 \%$ naturais e funcionais. Segundo dados da EUROMONITOR, $28 \%$ dos brasileiros consideram o valor nutricional o mais importante na hora de consumir um produto, enquanto $22 \%$ dá preferência a alimentos naturais e sem conservantes. A utilização de aditivos funcionais ganha extrema importância para os consumidores. Para um grande número de pessoas esses aditivos são um incentivo para a compra, elas querem um produto mais natural, sem conservantes, sem adição de açúcar e que traga benefícios para a sua saúde.

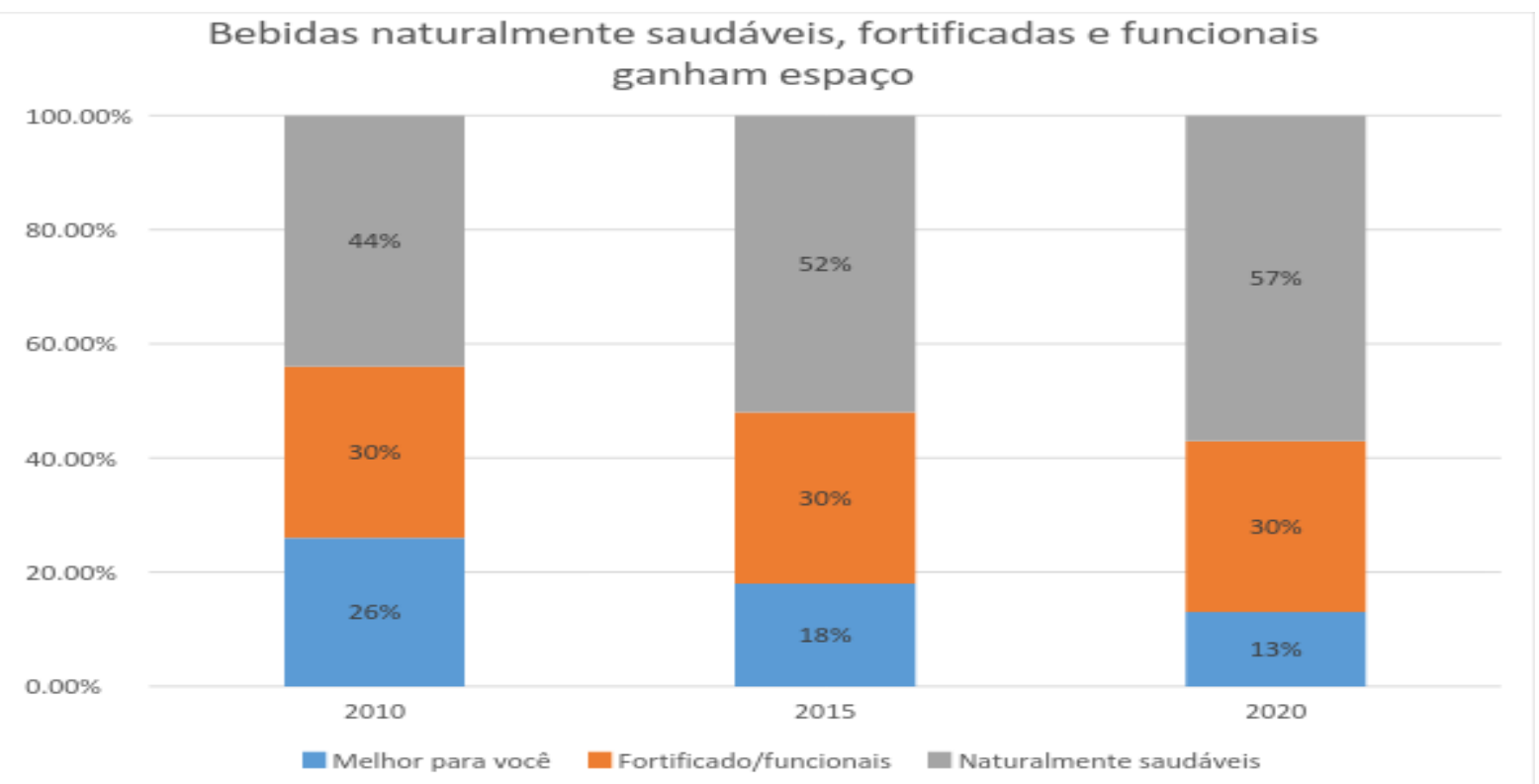

Figura 7: Bebidas saudáveis

Fonte: EUROMONITOR (2015) 
Primeiramente destinado a consumidores das classes $A$ e $B$, hoje os sucos naturais industrializados estão popularizados e mais acessíveis. De acordo com a Dunnhumby, empresa de pesquisa do grupo Tesco, entre os consumidores das classes $C$ e $D$ também cresce a preocupação com a saúde.

Segundo estudo global do Instituto TNS, encomendado pela GNT (fabricante mundial de ingredientes), no topo da lista negra dos consumidores estão os conservantes, os corantes e os edulcorantes artificiais visto que $60 \%$ dos consumidores evitam esses produtos ao comprarem alimentos e bebidas. Segundo a pesquisa, um baixo teor de gordura é um fator importante para $53 \%$ dos consumidores, ao passo que $51 \%$ procuram por produtos com teor de açúcar reduzido.

Analisando o comportamento do consumidor desse tipo de produto, observa-se claramente a ligação de autoconceito que o consumidor constrói com o produto, pois muita gente o consome também como forma de estabelecer sua identidade social.
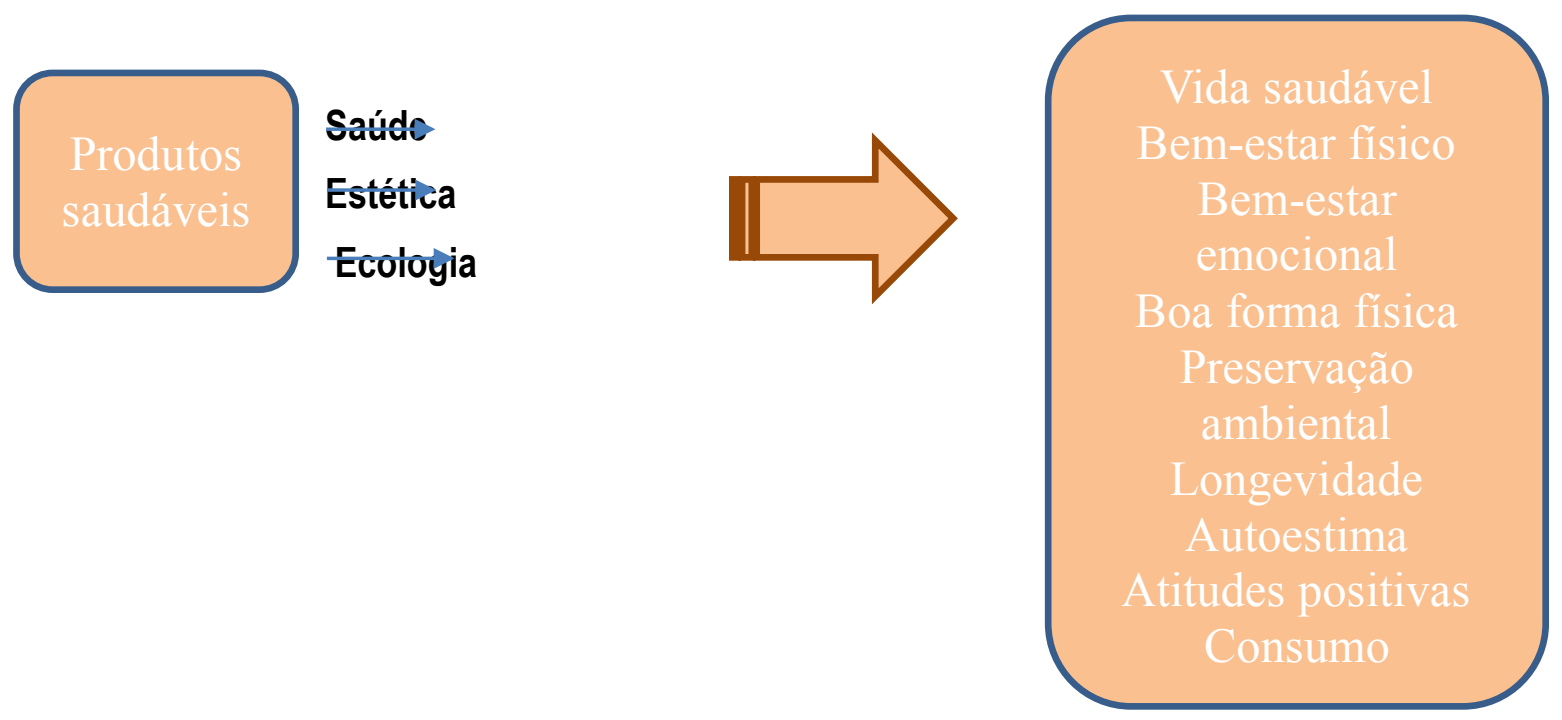

É exatamente esse o público-alvo da Agus. Pessoas que valorizam a saúde e prezam pelo bem-estar, que estão preocupadas em investir em um futuro positivo em todos os aspectos de suas vidas, principalmente na alimentação.

Pensando em termos de renda, o consumidor Agus é, principalmente, da classe A, aquele que tem mais acesso a informações e se propõe a pagar mais por um produto de qualidade com grande valor agregado. Dessa maneira, nossa estratégia de segmentação foi baseada em critérios comportamentais.

\section{Concorrência}

Hoje, existem sete pequenos produtores de Kombucha no Brasil. Desses sete, somente três atuam no Rio de Janeiro. Os restantes estão divididos entre Santa Catarina, Rio Grande do Sul e São Paulo.

Nenhum deles produz a bebida com frutas orgânicas. Isso significa que a Agus nasce com uma boa vantagem competitiva. As marcas se diferenciam variando em sabor e quantidade de $\mathrm{ml}$ por garrafa, normalmente sendo entre $200 \mathrm{ml}$ e $350 \mathrm{ml}$, e os sabores são diversos. Por conta das peculiaridades do produto, é inviável o seu transporte por longas distâncias, isso reduz o risco de concorrentes lançarem mão de estratégias predatórias de invasão de mercado.

A Agus acredita que a relação entre os produtores deve ser baseada em apoio e cooperação. Todas as empresas do ramo são recentes e existem muitos potenciais consumidores que ainda não conhecem 0 produto. Há muito para se desenvolver nesse mercado e os esforços das partes devem se concentrar na conscientização do consumidor quanto ao produto e seus benefícios, assim todos podem sair ganhando. 


\section{Comparação entre concorrentes}

A tabela abaixo foi construída com base na nossa análise acerca dos principais concorrentes da Agus e mostra uma breve comparação entre eles.

\begin{tabular}{|l|l|l|l|l|l|}
\hline $\begin{array}{l}\text { Fatores Críticos } \\
\text { Concorrentes }\end{array}$ & Qualidade & Orgânico & Preço & $\begin{array}{l}\text { Variedade } \\
\text { de prod. }\end{array}$ & $\begin{array}{l}\text { Responsabilidade } \\
\text { social }\end{array}$ \\
\hline Agus & Muito boa & Sim & Alto & Baixa & Sim \\
\hline K. & Muito boa & Não & Alto & Alta & Não \\
\hline TaoKombucha & Muito Boa & Não & Médio & Baixa & Não \\
\hline BioZen & Muito boa & Não & Alto & Baixa & Não \\
\hline CháVivo & Muito boa & Não & Médio & Baixa & Não \\
\hline
\end{tabular}

Tabela 3: Comparação entre concorrentes

Fonte: Elaboração própria

A partir da análise da tabela podemos perceber que os quatro concorrentes apresentam boa qualidade nos seus produtos, mas somente a Agus traz um produto orgânico. Em contrapartida, nos quesitos variedade de produtos e preço, não obtivemos um desempenho melhor do que os concorrentes, mas isso se explica pelo fato de a empresa ser muito recente e por isso ainda não teve tempo para desenvolver novos produtos ou ganhar escala para reduzir preços. Esses são fatores que devem ser cuidados com maior atenção pela Agus para obter vantagens futuras em relação aos seus concorrentes. E somente a Agus tem iniciativas de responsabilidade social, a começar com a sua própria fábrica por ter menor impacto ambiental e investimento em projetos sociais no âmbito ambiental.

\section{Planejamento Estratégico}

Somos uma empresa consciente e nos preocupamos com o bem-estar de todos os nossos stakeholders, inclusive com o meio ambiente.

\section{Missão}

Promover saúde para os nossos clientes através de bebidas naturais e funcionais, respeitando e preservando o meio ambiente.

\section{Visão}

Tornar-se referência de qualidade no mercado de bebidas saudáveis, atendendo às cidades Rio de Janeiro e São Paulo, dentro de três anos.

\section{Valores}

O valor central da Agus é promover saúde, este será sempre um Norte para empresa. Outros valores que compõem a cultura da organização são sustentabilidade, colaboração e comprometimento. 


\section{Análise SWOT}

A seguir, apresenta-se uma relação das principais forças, oportunidades, fraquezas e ameaças para a fase inicial do empreendimento.

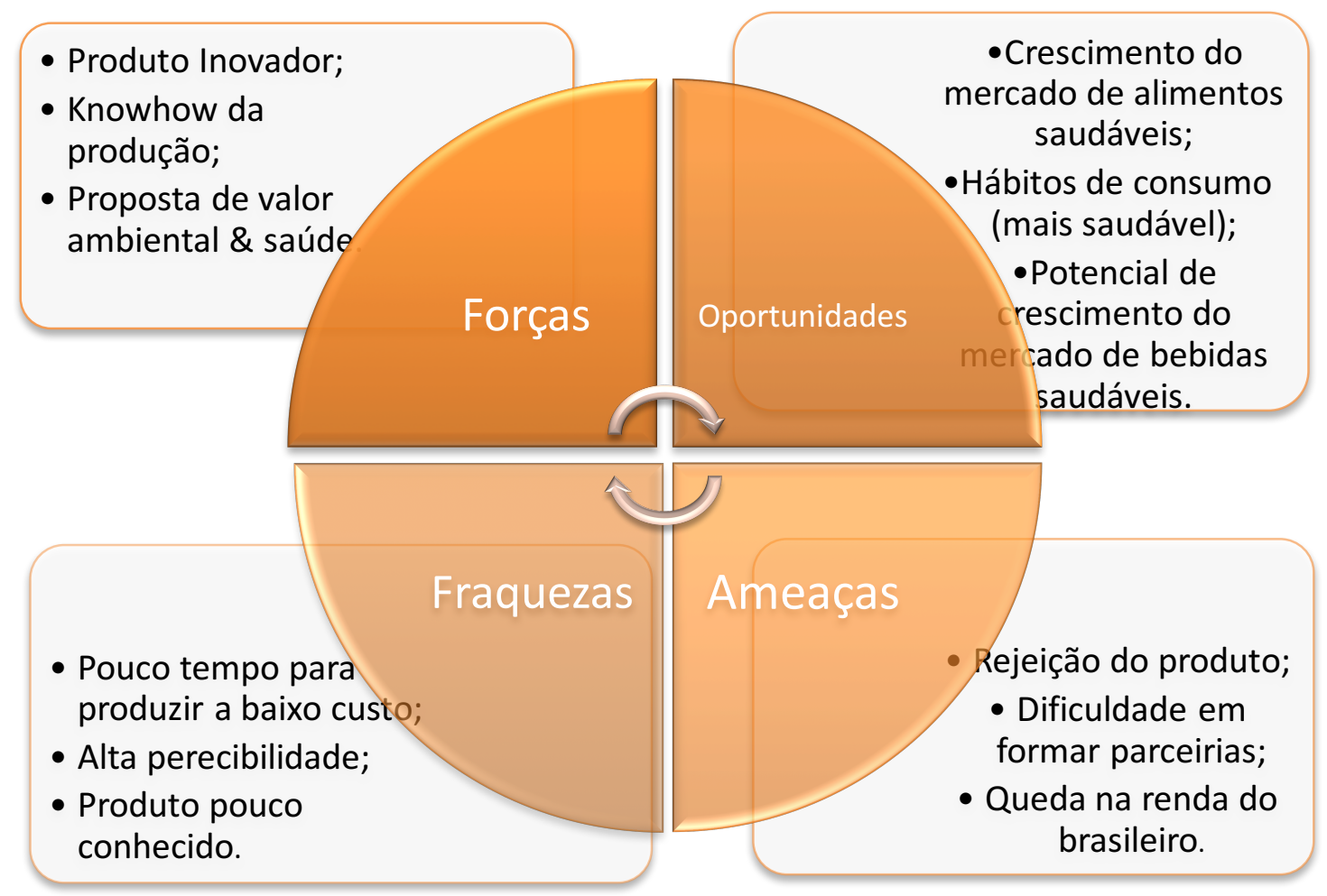

A principal força da Agus pode ser também sua maior ameaça porque trazer algo inovador para o mercado não é tarefa simples. A incerteza sobre a aceitação do produto dificulta o processo de tomada de decisão. Portanto, nossa estratégia será concentrar esforços na conscientização do público a cerca dos benefícios do produto e potencializar esses esforços trazendo junto ao produto uma forte proposta de valor ambiental para a empresa.

Seguindo a mesma ideia, a melhor oportunidade é confrontada pelo fato do seu produto ser ainda pouco conhecido. $O$ crescimento do mercado de alimentação saudável aliado ao potencial de crescimento do nicho de bebidas saudáveis é o melhor cenário para o desenvolvimento da Agus, e por isso devemos garantir uma boa apresentação do nosso produto e da nossa empresa.

\section{Marketing e Vendas}

\section{Qual é o nosso produto?}

Kombucha. É um alimento probiótico, microbiológico. Ajuda a regenerar a flora intestinal e é excelente para a saúde como um todo. A Agus vai produzir essa bebida e acrescentar a ela frutas orgânicas e outros ingredientes, que trarão sabores únicos e deliciosos para o tradicional Kombucha.

\section{0 que é Kombucha?}

Kombucha é uma bebida que promove a saúde e um remédio natural feito a partir da fermentação do chá preto. É proveniente de uma colônia composta de microorganismos aglomerados em uma massa de celulose parecida com uma panqueca, conhecida como Scooby. Quando o Scooby é colocado numa vasilha contendo uma mistura de chá e açúcar, transforma o líquido em uma bebida refrescante levemente borbulhante, doce e azeda com uma fragrância frugal muito saborosa que fornece diversos ácidos e nutrientes, excelentes para a saúde. A cultura de Kombucha se alimenta do açúcar e, na troca, produz outras 
substâncias valiosas que se formam na bebida: o ácido glucurônico, ácido glucônico, ácido láctico, vitaminas, aminoácidos, substâncias antibióticas. Dentre outras substâncias, o álcool de $0.5 \%$ a $1 \%$ também é produzido, mas não caracteriza bebida alcoólica.

O Kombucha evoluiu aparentemente de organismos do gênero das plantas há 2.5 bilhões de anos atrás. Diversas pessoas têm preparado essa espécie de chá fermentado para beber durante séculos, há mais de 2.000 anos. $O$ fato de estar presente até hoje é, em si, um testemunho de que as milhares de pessoas de todo o mundo, durante séculos, encontraram nele o seu grandioso valor.

\section{Linha Agus}

Nossa linha de produtos, inicialmente, terá pouca amplitude e profundidade, contando apenas com quatro sabores especiais, já testados e aprovados por consumidores com ampla experiência em cultivo de Kombucha. Nesse primeiro momento disponibilizaremos somente um tamanho de embalagem para simplificar o processo e baratear o produto.

\begin{tabular}{|l|l|}
\hline Sabores & Tamanho \\
\hline Uva & $250 \mathrm{ml}$ \\
\hline CHAl (Gengibre e especiarias) & $250 \mathrm{ml}$ \\
\hline Hibisco com gengibre & $250 \mathrm{ml}$ \\
\hline Matchá com limão & $250 \mathrm{ml}$ \\
\hline
\end{tabular}

\section{Tabela 4: Linha de produtos Agus}

Fonte: Elaboração própria.

\section{Evolução prevista do produto}

Depois que a produção já estiver em andamento e, quando identificarmos a aceitação do produto pelo público e a demanda por novas ofertas, pretendemos aprofundar a nossa linha de produtos desenvolvendo novos sabores e ampliá-la oferecendo novos tamanhos de embalagens.

\section{Estratégias de entrada no mercado}

A Agus utilizará duas principais estratégias de entrada no mercado. Primeiro, realizando parcerias com profissionais da área da saúde e com personalidades influentes no meio digital e que estejam ligados ao estilo de vida saudável para ajudarem a esclarecer possíveis dúvidas sobre o produto e divulgar a marca. E a segunda estratégia será realizar pontos de degustação em feiras de produtos orgânicos e eventos que tenham alguma relação com estilo de vida saudável. 

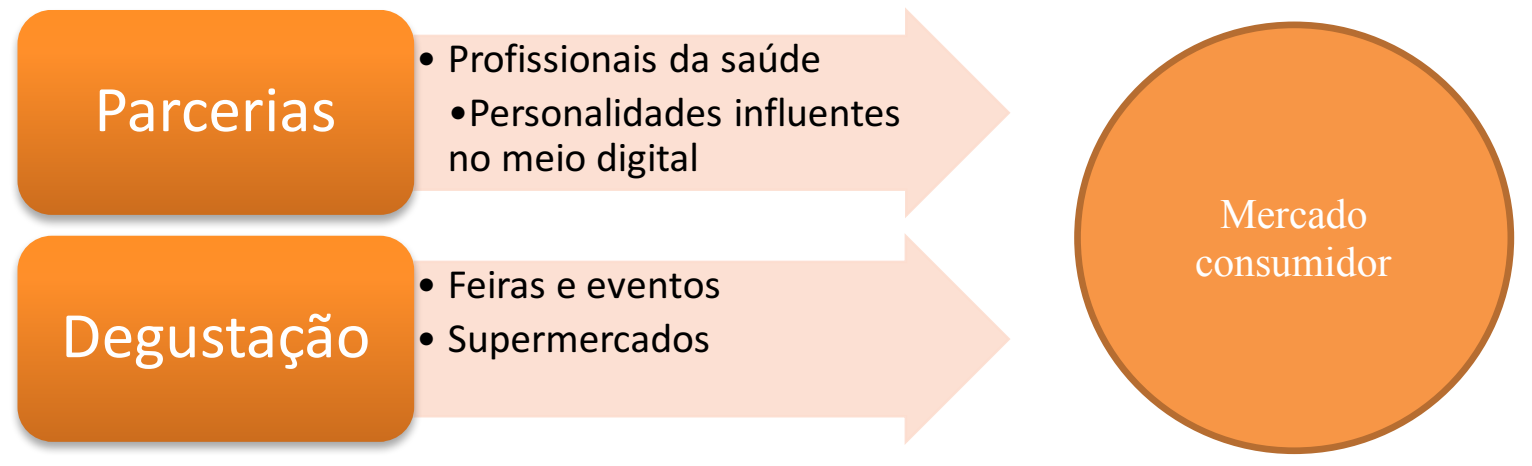

\section{Formação de preço}

Nossa política de precificação é simples. Em primeiro lugar, será cobrado o mesmo valor para todos os sabores da bebida. A diferença será somente para as garrafas de $250 \mathrm{ml}$ e $1 \mathrm{~L}$.

O preço será definido com base em quatro aspectos:

- Deve ser próximo ao praticado pela concorrência.

- Deve cobrir os custos de produção e distribuição.

- Deve garantir a viabilidade para melhorias, desenvolvimento e inovações.

- Quanto o nosso público está disposto a pagar pelo benefício do nosso produto?

Considerando esses quatro pontos, um valor de aproximadamente $\mathrm{R} \$ 22,90$ por garrafa de $250 \mathrm{ml}$ e $\mathrm{R} \$$ 59,90 por garrafa de $1 \mathrm{~L}$, seria o mais próximo do preço real a ser ofertado pela Agus.

\section{Distribuição}

A distribuição é um ponto muito relevante da nossa estratégia porque que o produto proposto apresenta um alto grau de perecibilidade. Por isso, acreditamos que terceirizar o serviço de distribuição, formando parcerias com transportadoras especializadas nessa atividade, seja uma ótima decisão.

Agus

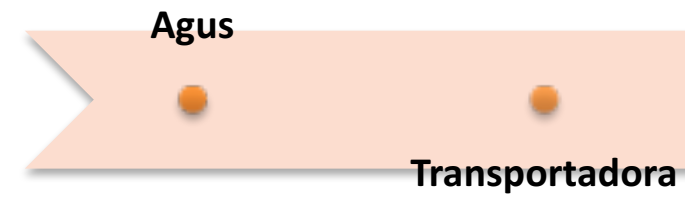

Varejo

\section{Cliente}

Os principais canais de vendas do Kombucha Agus serão supermercados que tenham área dedicada à produtos orgânicos (ex. Pão de Açúcar e Hortifruti) e lojas de varejo dedicadas à venda de produtos naturais (ex. Mundo Verde). Outro canal de vendas será através do nosso próprio site, nessa modalidade a distribuição será um pouco diferente pois o produto não passará pelo varejista, indo direto da transportadora para o cliente.

\section{Promoção}

A promoção é um fator crítico para a estratégia da empresa visto que o Kombucha é um produto ainda pouco conhecido pela maioria do público. É de grande importância conscientizar o consumidor sobre os benefícios do produto e apresentar a marca, ressaltando o seu diferencial.

Criaremos um canal próprio da marca no Youtube com vídeos que tragam dicas de saúde no dia a dia e conteúdo informativo sobre nutrição, com foco em nutrição saudável, orgânica e balanceada.

Também utilizaremos o Google Adwords para promover a marca no meio digital e conseguir melhores 
resultados nos buscadores online.

\section{Relacionamento com o cliente}

Para cultivar o melhor relacionamento com os nossos prezadíssimos clientes apostaremos em uma abordagem bem pessoal e acolhedora, onde o cliente terá voz ativa e haja interação entre as partes. 0 nosso atendimento ao público será inteiramente via canais digitais, especialmente redes sociais. Para isso, criaremos uma Página da marca no Facebook, um perfil no Twitter e um perfil no Instagram.

A ideia é muito mais ampla do que somente a utilizar as redes sociais como plataforma de atendimento. Envolve produção de conteúdo para gerar conversas relevantes, estratégias para aumentar as menções da marca e interações com o público para elevar os índices de engajamento e conversão. E ainda poderemos analisar as informações recebidas quando o consumidor entrar em contato ativo, e também interceptar e analisar menções espontâneas à marca.

\section{Finanças}

\section{Investimentos pré-operacionais}

A maior parte dos custos de investimentos provém dos 11 módulos de containers, e por isso é importante esclarecer que esses containers já vêm devidamente equipados com toda parte elétrica, piso e todos os acabamentos necessários assim como alguns equipamentos essenciais como privadas e pias no módulo destinado à área de banheiro. 0 custo também já inclui o transporte a instalação dos mesmos.

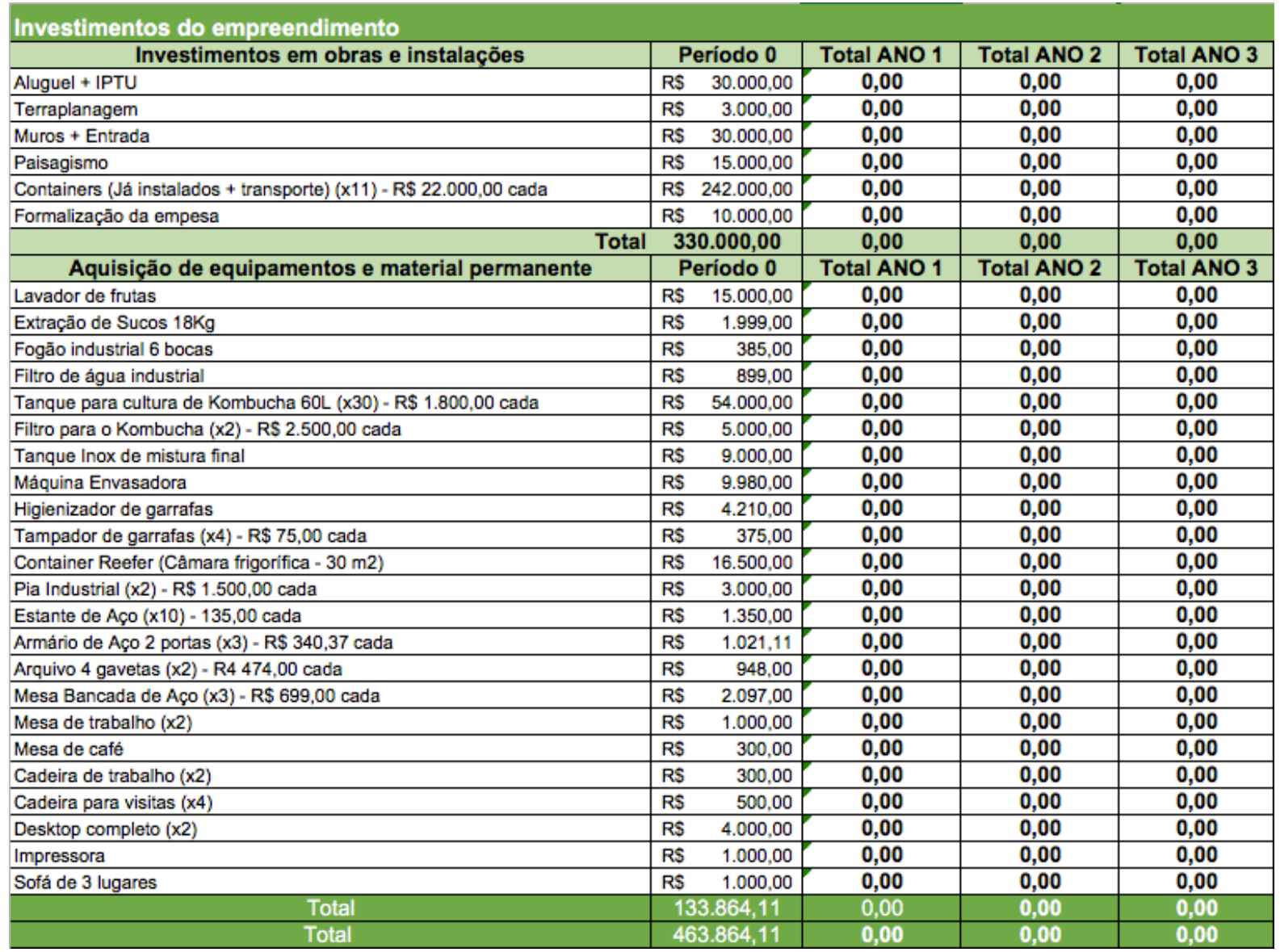

Tabela 5: Investimentos do empreendimento

Fonte: Elaboração própria. 


\section{Projeção de receitas}

A projeção de receitas foi feita considerando-se que a Agus produziria 120 Litros de Kombuchá por dia. 30 Litros para cada uma das 4 opções de sabor. Sendo 60 garrafas de $1 \mathrm{~L}$ por dia e 240 garrafas de $250 \mathrm{ml}$ por dia.

\begin{tabular}{|c|c|c|c|c|c|c|}
\hline \multicolumn{7}{|l|}{ Projeção de Vendas } \\
\hline \multicolumn{4}{|c|}{ Quantidade } & Total ANO 1 & Total ANO 2 & Total ANO 3 \\
\hline \multicolumn{4}{|c|}{ Garrafa $250 \mathrm{ml}$} & 57600 & 57600 & 57600 \\
\hline \multicolumn{4}{|c|}{ Garrafa 1L } & 14400 & 14400 & 14400 \\
\hline \multicolumn{4}{|c|}{ Demanda Total ....〉〉> } & 72000 & 72000 & 72000 \\
\hline Preço & Valor & Reajuste anual & \multirow{4}{*}{ Receita de Vendas } & Total ANO 1 & Total ANO 2 & Total ANO 3 \\
\hline Garrafa 250ml & 22,9 & $1 \%$ & & $1.319 .040,00$ & $1.332 .230,40$ & $1.345 .552,70$ \\
\hline Garrafa 1L & 59,9 & $1 \%$ & & $862.560,00$ & $871.185,60$ & $879.897,46$ \\
\hline \multicolumn{3}{|c|}{ Total de Vendas } & & $2.181 .600,00$ & $2.203 .416,00$ & $2.225 .450,16$ \\
\hline
\end{tabular}

Tabela 6: Projeção de vendas

Fonte: Elaboração própria.

\section{Projeção de custos e despesas}

\begin{tabular}{|c|c|c|c|}
\hline \multicolumn{4}{|l|}{ Projeção de custos } \\
\hline Custos com produtos & Total ANO 1 & Total ANO 2 & Total ANO 3 \\
\hline Garrafas 250ml (x240/dia) - RS 1,63 cada & $93.888,00$ & $93.888,00$ & $93.888,00$ \\
\hline Garrafas 1L (x60/dia) - RS 2,27 cada & $32.688,00$ & $32.688,00$ & $32.688,00$ \\
\hline Água Mineral (120L/dia) - R\$ 120,00 dia & $28.800,00$ & $28.800,00$ & $28.800,00$ \\
\hline Açúcar (6kg/dia) - RS 17,40 dia & $4.176,00$ & $4.176,00$ & $4.176,00$ \\
\hline Chá Preto/Verde $(0,6 \mathrm{~kg} / \mathrm{dia})$ - RS $35,00 \mathrm{dia}(1 \mathrm{Kg})$ & $8.400,00$ & $8.400,00$ & $8.400,00$ \\
\hline \begin{tabular}{|l|} 
Uvas (6kg/dia) - RS 29,22 dia \\
\end{tabular} & $7.012,80$ & $7.012,80$ & $7.012,80$ \\
\hline Gengibre $(0,3 \mathrm{Kg} / \mathrm{dia})-\mathrm{RS} 6,00(1 \mathrm{Kg})$ & $1.440,00$ & $1.440,00$ & $1.440,00$ \\
\hline Hibisco $(0,36 \mathrm{Kg} /$ dia $)-\mathrm{R} \$ 401 \mathrm{Kg}$ & $4.800,00$ & $4.800,00$ & $4.800,00$ \\
\hline Limão (1 Kg/dia) RS 2,00 $1 \mathrm{Kg}$ & 240,00 & 240,00 & 240,00 \\
\hline Erva mate $(0,36 \mathrm{Kg} / \mathrm{dia})-\mathrm{RS} 12,001 \mathrm{Kg}$ & $2.880,00$ & $2.880,00$ & $2.880,00$ \\
\hline Especiarias (0,1 Kg/dia) $\mathrm{R} \$ 10,00$ dia & $2.400,00$ & $2.400,00$ & $2.400,00$ \\
\hline (i & $186.724,80$ & $186.724,80$ & $186.724,80$ \\
\hline Custos com serviços & Total ANO 1 & Total ANO 2 & Total ANO 3 \\
\hline Transportadora (apróx. 15\% preço) & $325.152,00$ & $325.152,00$ & $325.152,00$ \\
\hline Total & $325.152,00$ & $325.152,00$ & $325.152,00$ \\
\hline Total & $511.876,80$ & $511.876,80$ & $511.876,80$ \\
\hline
\end{tabular}

Tabela 7: Projeção de custos

Fonte: Elaboração própria.

Custo com profissionais (seus funcionários diretamente envolvidos com a produçäo dos bens ou serviços)
\begin{tabular}{|c|c|c|c|c|c|c|c|}
\hline \multicolumn{1}{|c|}{ Tipo de profissional } & Custo mensal? & Salário & $\%$ de encargos & Quantidade & Total ANO1 & Total ANO2 & Total AN03 \\
\hline Linha de produção & SIM & R\$ $1.500,00$ & $35 \%$ & 2 & $51.600,00$ & $51.600,00$ & $51.600,00$ \\
\hline Químico industrial & SIM & R\$ 4.000,00 & $35 \%$ & 1 & $68.800,00$ & $68.800,00$ & $68.800,00$ \\
\hline Total de Custos com Pessoal & & & & & $120.400,00$ & $120.400,00$ & $120.400,00$ \\
\hline
\end{tabular}

Tabela 8: Custo com Profissionais

Fonte: Elaboração própria. 


\begin{tabular}{|c|c|c|c|c|c|c|}
\hline Tipo de profissional & Salário & $\%$ de encargos & Quantidade & Total ANO 1 & Total ANO 2 & Total ANO 3 \\
\hline Secretária & $2.000,00$ & $35 \%$ & 1 & $34.400,00$ & $34.400,00$ & $34.400,00$ \\
\hline Vendedor & $1.500,00$ & $35 \%$ & 1 & $25.800,00$ & $25.800,00$ & $25.800,00$ \\
\hline \multicolumn{4}{|c|}{ Total de Despesas com Pessoal } & $34,400,00$ & $34.400,00$ & $34.400,00$ \\
\hline
\end{tabular}

Tabela 9: Despesas com pessoal

Fonte: Elaboração própria.

\begin{tabular}{|c|c|c|c|c|c|}
\hline \multicolumn{6}{|l|}{ Projeção das Despesas Cerais } \\
\hline Administrativas e de escritório & Item mensal? & Valor mensal & Total ANO 1 & Total ANO 2 & Total ANO 3 \\
\hline Internet & $\operatorname{sim}$ & 300,00 & $3.600,00$ & $3.600,00$ & $3.600,00$ \\
\hline Luz & sim & $4.000,00$ & $48.000,00$ & $48.000,00$ & $48.000,00$ \\
\hline Água & sim & $2.000,00$ & $24.000,00$ & $24.000,00$ & $24.000,00$ \\
\hline Telefone & sim & 300,00 & $3.600,00$ & $3.600,00$ & $3.600,00$ \\
\hline Material de escritório & sim & 500,00 & $6.000,00$ & $6.000,00$ & $6.000,00$ \\
\hline Aluguel + IPTU & sim & $30.000,00$ & $360.000,00$ & $360.000,00$ & $360.000,00$ \\
\hline \multicolumn{3}{|l|}{$\begin{array}{ll} & \text { Total } \\
\end{array}$} & $445.200,00$ & $445.200,00$ & $445.200,00$ \\
\hline Marketing e comercialização & Item mensal? & Valor mensal & Total ANO 1 & Total ANO 2 & Total ANO 3 \\
\hline Propaganda ( $5 \%$ do faturamento) & $\operatorname{sim}$ & R\$ $\quad 9.090,00$ & $109.080,00$ & $109.080,00$ & $109.080,00$ \\
\hline Adwords ( $5 \%$ do faturamento) & sim & $9.090,00$ & $109.080,00$ & $109.080,00$ & $109.080,00$ \\
\hline \multicolumn{3}{|c|}{ Total } & $218.160,00$ & $218.160,00$ & $218.160,00$ \\
\hline Serviços de terceiros & Item mensal? & Valor mensal & Total ANO 1 & Total ANO 2 & Total ANO 3 \\
\hline Limpeza + jardinagem & $\operatorname{sim}$ & R\$ $\quad 13.000,00$ & $156.000,00$ & $156.000,00$ & $156.000,00$ \\
\hline Segurança (R\$ 2.063,33/1 seg) & sim & $8.253,32$ & $99.039,84$ & $99.039,84$ & $99.039,84$ \\
\hline \multicolumn{3}{|l|}{ - } & $255.039,84$ & $255.039,84$ & $255.039,84$ \\
\hline Outras despesas & Item mensal? & Valor mensal & Total ANO 1 & Total ANO 2 & Total ANO 3 \\
\hline Seguro & $\operatorname{sim}$ & R\$ $\quad 2.500,00$ & $30.000,00$ & $30.000,00$ & $30.000,00$ \\
\hline \multicolumn{3}{|c|}{ Total } & $30.000,00$ & $30.000,00$ & $30.000,00$ \\
\hline \multicolumn{2}{|c|}{ Total das Despesas } & & $948.399,84$ & $948.399,84$ & $948.399,84$ \\
\hline
\end{tabular}

Tabela 10: Projeção das despesas gerais

Fonte: Elaboração própria.

\section{Resultados}

Base de cálculo para impostos

Percentual médio de impostos pagos sobre a venda de produtos Percentual médio de impostos pagos sobre o lucro

$8 \%$

$8 \%$

\begin{tabular}{|l|c|c|c|}
\hline \multicolumn{3}{|c|}{ Projeçăo de resultados } \\
\hline \\
\hline \multirow{2}{|c|}{ Ano 1 } & Ano 2 & Ano 3 \\
\hline Receita Bruta Total & $2.181 .600,00$ & $2.203 .416,00$ & $2.225 .450,16$ \\
\hline Garrafa 250ml & $1.319 .040,00$ & $1.332 .230,40$ & $1.345 .552,70$ \\
\hline Garrafa 1L & $862.560,00$ & $871.185,60$ & $879.897,46$ \\
\hline$(-)$ Impostos e deduçöes sobre vendas & $174.528,00$ & $176.273,28$ & $178.036,01$ \\
\hline Receita Liquida & $2.007 .072,00$ & $2.027 .142,72$ & $2.047 .414,15$ \\
\hline$(-)$ Custos dos produtos e serviços & $632.276,80$ & $632.276,80$ & $632.276,80$ \\
\hline Margem de Contribuiçäo & $1.374 .795,20$ & $1.394 .865,92$ & $1.415 .137,35$ \\
\hline Margem (\%) & $63 \%$ & $63 \%$ & $64 \%$ \\
\hline Despesas & $982.799,84$ & $982.799,84$ & $982.799,84$ \\
\hline Despesas administrativas e de escritório & $445.200,00$ & $445.200,00$ & $445.200,00$ \\
\hline Despesas de marketing e comercializaçāo & $218.160,00$ & $218.160,00$ & $218.160,00$ \\
\hline Despesas com serviços de terceiros & $255.039,84$ & $255.039,84$ & $255.039,84$ \\
\hline Outras despesas & $30.000,00$ & $30.000,00$ & $30.000,00$ \\
\hline Despesas com Pessoal & $34.400,00$ & $34.400,00$ & $34.400,00$ \\
\hline Lucro Bruto & $391.995,36$ & $412.066,08$ & $432.337,51$ \\
\hline$(-)$ Impostos s/ Lucro & $31.359,63$ & $32.965,29$ & $34.587,00$ \\
\hline Lucro Liquido & $360.635,73$ & $379.100,79$ & $397.750,51$ \\
\hline
\end{tabular}




\section{Arthur Couto de Azevedo}

Tabela 10: Resultados

Fonte: Elaboração própria.

\section{Fluxo de caixa}

\begin{tabular}{|c|c|c|c|c|}
\hline \multicolumn{5}{|l|}{ Fluxo de caixa } \\
\hline Entradas & Período 0 & Total ANO 1 & Total ANO 2 & Total ANO 3 \\
\hline Receitas & & $2.181 .600,00$ & $2.203 .416,00$ & $2.225 .450,16$ \\
\hline & & 0,00 & 0,00 & 0,00 \\
\hline Total & 0,00 & $2.181 .600,00$ & $2.203 .416,00$ & $2.225 .450,16$ \\
\hline Saídas & Período 0 & Total ANO 1 & Total ANO 2 & Total ANO 3 \\
\hline Deduções & & 0,00 & 0,00 & 0,00 \\
\hline Impostos sobre as vendas de produtos & & $174.528,00$ & $176.273,28$ & $178.036,01$ \\
\hline Impostos sobre o lucro & & $31.359,63$ & $32.965,29$ & $34.587,00$ \\
\hline Custos totais & & $632.276,80$ & $632.276,80$ & $632.276,80$ \\
\hline Despesas totais & & $982.799,84$ & $982.799,84$ & $982.799,84$ \\
\hline Investimento & $463.864,11$ & 0,00 & 0,00 & 0,00 \\
\hline Prólabore & & $72.000,00$ & $72.000,00$ & $72.000,00$ \\
\hline Total & $463.864,11$ & $1.892 .964,27$ & $1.896 .315,21$ & $1.899 .699,65$ \\
\hline Fluxo de caixa líquido & $-463.864,11$ & $288.635,73$ & $307.100,79$ & $325.750,51$ \\
\hline Fluxo de caixa acumulado & $-463.864,11$ & $-175.228,38$ & $131.872,41$ & $457.622,92$ \\
\hline Base de cálculo para impostos & $\%$ & & & \\
\hline Percentual médio de impostos pagos sobre a venda de produtos & $8 \%$ & & & \\
\hline Percentual médio de impostos pagos sobre o lucro & $8 \%$ & & & \\
\hline
\end{tabular}

Tabela 11: Fluxo de caixa

Fonte: Elaboração própria.

\section{Análise de investimento}

Mesmo trabalhando com cenários pessimistas e custos elevados a Agus mostrou-se um empreendimento rentável, apresentando uma TIR de 43\%, Payback de 19 meses, sempre lucrando.

\begin{tabular}{|c|c|c|}
\hline \multicolumn{2}{|c|}{ Fluxo de Caixa Líquido } & \multirow{2}{*}{$\begin{array}{l}\text { Taxa } \\
15 \% \\
\end{array}$} \\
\hline Investimento & $-463.864,11$ & \\
\hline Ano 1 & $288.635,73$ & \\
\hline Ano 2 & $307.100,79$ & \\
\hline Ano 3 & $325.750,51$ & \\
\hline & & \\
\hline$\overline{V P L}$ & R\$ 1.161.250,27 & \\
\hline TIR & \begin{tabular}{|l|}
$43 \%$ \\
\end{tabular} & \\
\hline
\end{tabular}

Tabela 12: análise de investimento.

Fonte: Elaboração própria.

\section{Necessidade de recursos e formas de obtenção}

Consideramos o investimento de recursos próprios da família para abrir o negócio. 


\section{ANEXO I}

Tabela 13: objetivos, metas, indicadores e ações estratégicas

\begin{tabular}{|c|c|c|c|}
\hline Objetivos & Metas & Indicadores & Ação \\
\hline \multirow{2}{*}{$\begin{array}{l}\text { Diversificar } \\
\text { fontes de } \\
\text { receitas }\end{array}$} & $\begin{array}{l}\text { Alcançar duas fontes de } \\
\text { receitas alternativas } \\
\text { dentro de dois anos }\end{array}$ & $\begin{array}{l}\text { Número de fontes de } \\
\text { receitas }\end{array}$ & $\begin{array}{l}\text { Criar conteúdo para } 0 \\
\text { youtube voltado para saúde } \\
\text { no dia a dia e monetizá- } \\
\text { lo; criar clube de assinaturas }\end{array}$ \\
\hline & $\begin{array}{l}\text { Atingir } 10 \% \text { das receitas } \\
\text { provenientes de fontes } \\
\text { alternativas dentro de } \\
\text { três anos }\end{array}$ & $\begin{array}{l}\text { Percentual das receitas } \\
\text { provenientes de fontes } \\
\text { alternativas }\end{array}$ & $\begin{array}{l}\text { Recrutar agentes de saúde } \\
\text { para criar conteúdo para o } \\
\text { youtube e buscar parcerias } \\
\text { para divulgar o clube de } \\
\text { assinaturas }\end{array}$ \\
\hline \multirow[b]{2}{*}{$\begin{array}{l}\text { Benefícios para } \\
\text { saúde }\end{array}$} & $\begin{array}{l}\text { Garantir a qualidade do } \\
\text { produto }\end{array}$ & Avaliação por especialistas & $\begin{array}{l}\text { Utilizar ingredientes naturais } \\
\text { e de qualidade }\end{array}$ \\
\hline & $\begin{array}{l}\text { Conscientizar sobre a } \\
\text { importância de manter } \\
\text { uma dieta equilibrada no } \\
\text { dia a dia }\end{array}$ & $\begin{array}{l}\text { Número de visualizações } \\
\text { nos canais com conteúdo } \\
\text { informativo }\end{array}$ & $\begin{array}{l}\text { Realizar campanhas de } \\
\text { conscientização sobre a } \\
\text { importância de manter um } \\
\text { dieta equilibrada no dia a dia }\end{array}$ \\
\hline \multirow{2}{*}{ Projetos sociais } & $\begin{array}{l}\text { Destinar, no mínimo, } 1 \% \\
\text { dos lucros para projetos } \\
\text { sociais }\end{array}$ & $\begin{array}{l}\text { Percentual do } \begin{array}{l}\text { lucro } \\
\text { investido em projetos } \\
\text { sociais }\end{array} \\
\end{array}$ & $\begin{array}{l}\text { Investir lucros em projetos } \\
\text { sociais }\end{array}$ \\
\hline & $\begin{array}{l}\text { Atuar em pelo menos } \\
\text { dois projetos sociais } \\
\text { dentro de dois anos }\end{array}$ & $\begin{array}{l}\text { Número de projetos sociais } \\
\text { envolvidos }\end{array}$ & $\begin{array}{l}\text { Engajar-se em projetos de } \\
\text { cunho social que tenham } \\
\text { afinidade com a proposta de } \\
\text { valor da Agus }\end{array}$ \\
\hline \multirow{2}{*}{$\begin{array}{l}\text { Eficácia } \\
\text { processo } \\
\text { produção }\end{array}$} & $\begin{array}{l}\text { Aumentar produção em } \\
100 \% \text { dentro de dois } \\
\text { anos }\end{array}$ & $\begin{array}{l}\text { Quantidade de } \begin{array}{l}\text { unidades } \\
\text { produzidas } \\
\text { mensalmente }\end{array} \\
\end{array}$ & $\begin{array}{l}\text { Implementar novas } \\
\text { tecnologias de produção no } \\
\text { segundo ano }\end{array}$ \\
\hline & $\begin{array}{l}\text { Manter perdas mensais } \\
\text { abaixo de } 3 \%\end{array}$ & $\begin{array}{l}\text { Percentual de perdas } \\
\text { mensais }\end{array}$ & $\begin{array}{l}\text { Controlar perdas e corrigir } \\
\text { possíveis causas }\end{array}$ \\
\hline \multirow{2}{*}{$\begin{array}{l}\text { Treinar e } \\
\text { desenvolver } \\
\text { colaboradores }\end{array}$} & $\begin{array}{l}\text { Manter } \quad 100 \% \text { dos } \\
\text { colaboradores treinados }\end{array}$ & $\begin{array}{l}\text { Número percentual de } \\
\text { colaboradores treinados }\end{array}$ & $\begin{array}{l}\text { Oferecer treinamento para } \\
\text { novos colaboradores }\end{array}$ \\
\hline & $\begin{array}{l}\text { Alocar } 100 \% \text { dos } \\
\text { colaboradores no projeto } \\
\text { de desenvolvimento } \\
\text { pessoal }\end{array}$ & $\begin{array}{l}\text { Eficácia do projeto medido } \\
\text { através do relatório dos } \\
\text { profissionais da área de } \\
\text { desenvolvimento pessoal }\end{array}$ & $\begin{array}{l}\text { Criar projeto } \\
\text { desenvolvimento pessoal }\end{array}$ \\
\hline
\end{tabular}




\section{Referências}

BREWERS ASSOCIATION. Brewers Association: craft continues to brew growth. Press Releases. Boulder, 18 mar. 2013.2 Disponivel em: http://www.brewersassociation.org/pages/media/pressreleases/show?title=brewers-association-craftcontinues-to-brew-growth. Acesso em maio 2017.

A sociedade limitada: aspectos jurídicos para empreendedores. Disponível em: http://www.hubjur.com.br/artigos_detalhe/?ald=8. Acesso em maio 2017.

Análise sobre 0 mercado e a indústria de Kombucha. Disponível em: http://www.grandviewresearch.com/industry-analysis/kombucha-market. Acesso em abril 2017.

OPORTUNIDADE DE NEGÓCIO ALIMENTOS FUNCIONAIS - SEBRAE-DF, BRASÍLIA, 2009.

Natural e orgânico: como a busca por mais saúde tem impactado o futuro do mercado de bebidas. Disponível em: https://pt.slideshare.net/Euromonitor/natural-e-orgnico-como-a-busca-por-mais-sade-tem-impactado-ofuturo-do-mercado-de-bebidas. Acesso em maio 2017.

ABRABE - ASSOCIAÇÃO BRASILEIRA DE BEBIDAS. Categorias. Disponível em: http://www.abrabe.org.br/categorias/. Acesso em maio 2017.

O SETOR DE BEBIDAS NO BRASIL, setorial 40 pg. 93-130 -BNDES, SP, 2014.

TROMBETA REIS, juliana. Setor de bebidas no Brasil abrangência e configuração preliminar - Revista Rosa dos Ventos, junho de 2015.

Kombucha: conheça 0 chá fitness milenar que conquistou famosas. Disponível em: http://revistamarieclaire.globo.com/Beleza/noticia/2017/03/ kombucha-conheca-o-cha-fitness-milenar-queconquistou-famosas.html. Acesso em junho 2017.

Kombucha: 0 chá milenar que promete emagrecer e dar energia. Disponível em: http://veja.abril.com.br/saude/kombucha-o-cha-milenar-que-promete-emagrecer-e-dar-energia/ . Acesso em junho 2017.

Setting up a kombucha continuous brew system. Disponível em: http://www.culturesforhealth.com/learn/kombucha/kombucha-continuous-brewing-system/. Acesso em junho 2017.

Choosing equipment for brewing kombucha. Disponível em: http://www.culturesforhealth.com/learn/kombucha/kombucha-equipment/. Acesso em junho 2017.

Informações gerais sobre cultura de kombucha. Disponível em: http://www.kombucha.blog.br. Acesso em: maio 2017.

Mercado de saudável movimenta 35 bilhões por ano no brasil. Disponível em: http://www.gazetadopovo.com.br/economia/mercado-saudavel-movimenta-us-35-bilhoes-por-ano-no-brasila2w7of1gwktt7ghup5wfo6z0. Acesso em Abril 2017.

Produtos saudáveis e naturais ganham preferência do consumidor movimentam mercado de sucos no brasil. Disponível em: http://www.marciorodrigues.com.br/mostraNoticia.php?codnoticia=646. Acesso em abril 2017.

Kombucha Market to grow 25\% each year to 2020. Disponível em: http://www.beveragedaily.com/Markets/Kombucha-market-to-grow-25-each-year-to-2020. Acesso em abril 2017. 